\title{
Salivary cortisol and cortisone responses to tetracosactrin (synacthen)
}

${ }^{1}$ Michael P Cornes, ${ }^{1}$ Helen L Ashby, ${ }^{2}$ Yasmeen Khalid, ${ }^{2}$ Harit N Buch, ${ }^{1}$ Clare Ford,

${ }^{1,3}$ Rousseau Gama

Departments of ${ }^{1}$ Clinical Chemistry and ${ }^{2}$ Diabetes, New Cross Hospital,

Wolverhampton, West Midlands and ${ }^{3}$ Research Institute, Healthcare Sciences,

Wolverhampton University, Wolverhampton, West Midlands.

Running Title: SST using salivary cortisol and cortisone

Keywords: Saliva, cortisol, cortisone, synacthen, tetracsoactrin

\section{Correspondence to:}

Dr Michael Cornes

\section{Clinical Chemistry,}

New Cross Hospital,

\section{Wolverhampton, WV10 0QP,}

UK.

Tel: 01902307999 ext 8261

Fax: 01902695618

E-Mail: michael.cornes@nhs.net

DECLARATIONS

Competing interests: None

Funding: None

Ethical approval: Not required. This was a service evaluation

Guarantor: RG

Contributorship: HA, YK and HB were responsible for patient recruitment and sample collection. MC set up and analysed all specimens. HB, RG and CF conceived the idea. $\mathrm{MC}$ and RG wrote the initial manuscript. All authors reviewed the data and edited the paper. 


\begin{abstract}
Background

To establish cut-off values for salivary LC-MS/MS cortisol and cortisone in defining adequate adrenocortical function during a standard synacthen test.

\section{Methods}

We compared salivary LC-MS/MS cortisol and cortisone responses to those of serum cortisol measured on the Roche E170 immunoassay analyser and the Abbot Architect i2 2000 before and 30 minutes and 60 minutes following $0.25 \mathrm{mg}$ of intravenous synacthen.

\section{Results}

Correlation of salivary cortisol and cortisone were bimodal and linear respectively. Based on these correlations, adequate salivary cortisol and cortisone responses to synacthen were extrapolated from a serum cortisol (Roche) cut-off of $550 \mathrm{nmol} / \mathrm{L}$ and defined as $15 \mathrm{nmol} / \mathrm{L}$ and $45 \mathrm{nmol} / \mathrm{L}$ respectively. The Abbott method correlated well with the Roche but gave results that were about $20 \%$ lower than the Roche method.

\section{Conclusions}

Measurement of salivary cortisol and cortisone responses offer an alternative to those of serum cortisol during a synacthen test in the investigation of adrenal hypofunction.
\end{abstract}




\section{Introduction}

Cortisol circulates as free cortisol $(<5 \%)$ but mostly bound to the carrier proteins cortisol binding globulin (CBG) and albumin. Serum cortisol, however, is a measurement of free and bound cortisol and in conditions of altered CBG levels, such as acute illness or oestrogen therapy, it may be misleading as it does not accurately reflect serum free cortisol. Cortisol in saliva, however, accurately reflects serum free cortisol as it is unbound and in equilibrium with circulating free cortisol [1-3].

Cortisol in the salivary glands is deactivated by $11 \beta$-hydroxysteroid dehydrogenase type $2(11 \beta$-HSD2) to cortisone. Salivary cortisol concentrations are, therefore, dependent upon circulating free cortisol and its metabolism by salivary $11 \beta$-HSD2 to cortisone. Circulating free and bound cortisone are stable in their basal state and following adrenal stimulation and therefore their contribution to salivary cortisone is constant [1-3]. Increases in salivary cortisone are, therefore, solely due to its conversion from salivary cortisol by $11 \beta$-HSD2. This indicates that salivary cortisol and cortisone may be better biomarkers of adrenal function than serum cortisol. The low salivary cortisone and cortisol concentrations, which are ten fold and thirty fold lower than serum total cortisol concentrations respectively, however precluded their accurate and reliable measurement until the advent of liquid chromatography tandem mass spectroscopy (LC-MS/MS).

We have encountered patients, referred for synacthen tests to exclude adrenal failure, who have extremely difficult venous access. Multiple attempts of often unsuccessful cannulation are extremely distressing for them. In these patients assessment of adrenal function using salivary cortisol instead of serum cortisol would circumvent the problem. There is, however, paucity of data on salivary LC-MS/MS cortisol and cortisone responses to synacthen.

We, therefore, compared salivary cortisol and cortisone responses to those of serum cortisol during a standard $0.25 \mathrm{mg}$ synacthen test. Appropriate cut-offs for salivary cortisol and cortisone defining adequate adrenocortical function during a synacthen test were extrapolated from widely accepted serum cortisol cut off values. 


\section{Subjects and Methods}

\section{Patients}

In a six month prospective evaluation study, outpatients attending the endocrine and metabolic dynamic function clinic for a short synacthen test for possible adrenal insufficiency were recruited. Inclusion criteria included those willing to participate who did not have periodontal disease and t were not taking or had not recently received either oestrogens or glucocorticoids. All patients had simultaneous blood and saliva samples as detailed below.

\section{Short synacthen test (SST)}

Short synacthen tests were performed in the afternoon. An intravenous cannula was inserted into an antecubital fossa vein and baseline blood and saliva samples were collected between $14.00 \mathrm{~h}$ and $14.30 \mathrm{~h}$. Two hundred and fifty micrograms of Tetracosactide (Synacthen, Alliance Pharmaceuticals Ltd, Chippenham, UK) was then administered intravenously and further blood and salivary samples collected 30 and 60 minutes later. Blood and saliva samples were collected into Sarstedt serum/z4 gel tube (Sarstedt Safety Monovette serum Z/4 2, Aktiengesellschaft \& Co, Germany) and Salivette tubes (Plain cotton swab; Sarstedt, Numbrecht, Germany) respectively.

Blood was separated and serum cortisol measured by electrochemiluminescence immunoassay (Elecsys Cortisol, Roche Diagnostics GmbH, Mannheim, Germany) on the Roche Modular Analytics E170 immunoassay analyser and by a chemiluminescence microparticle immunoassay on an Abbot Architect i2000 (Abbott Laboratories, USA). Salivary samples were centrifuged at 3000rpm for 5 minutes. The cotton was then discarded and the extracted saliva frozen at $-80 \mathrm{C}$ until analysis for cortisol and cortisone by LC-MSMS. LC-MSMS analysis was performed on a Shimadzu Prominence HPLC system coupled to an ABSciex 3200 mass spectrometer based on a previously described method $[4,5]$. The only differences were the use of phenomenex C8 guard cartridges (AJO-4289) for the solid phase extraction steps and the platform used. The method was validated in-house and via sample exchange prior to the study.

The Elecsys Cortisol assay has a detection limit of 2nmol/L (pack insert; Elecsys Cortisol, Roche Diagnostics GmbH, Mannheim, Germany) with intra-assay and interassay coefficients of variation (cv) of $1.1 \%$ at $418 \mathrm{nmol} / \mathrm{L}$ and $1.7 \%$ at $410 \mathrm{nmol} / \mathrm{L}$ respectively (in-house data). The Abbott Architect cortisol assay has a detection limit of $22 \mathrm{nmol} / \mathrm{L}$ (pack insert; Abbott Laboratories, USA) with intra-assay and inter-assay cvs of $4.3 \%$ and $3.2 \%$ at $103 \mathrm{nmol} / \mathrm{L}$ and $374 \mathrm{nmol} / \mathrm{L}$ respectively. Cross reactivity in the cortisol assay due to cortisone is $2.7 \%$ for the Abbott Architect (pack insert; Abbott Laboratories, USA) and $0.3 \%$ for the Elecysys (pack insert; Elecsys Cortisol, Roche Diagnostics GmbH, Mannheim, Germany). Both the LC-MSMS cortisol and cortisone assays have a detection limit of $0.25 \mathrm{nmol} / \mathrm{L}$. The intra-assay cv for cortisol and cortisone were $4.9 \%$ at $9.5 \mathrm{nmol} / \mathrm{L}$ and $4.9 \%$ at $9.5 \mathrm{nmol} / \mathrm{L}$ respectively and the inter-assay cv for cortisol and cortisone were $10.8 \%$ at $9.7 \mathrm{nmol} / \mathrm{L}$ and $6.0 \%$ at 10 $\mathrm{nmol} / \mathrm{L}$ respectively (in-house data).

A normal cortisol response to synacthen was defined as a post-stimulation peak Roche Elecsys cortisol value of $\geq 550 \mathrm{nmol} / \mathrm{L}$ at either 30 or 60 minutes [8]. 


\section{Results}

Thirty-six patients (16 female) with a mean age 51y (range 15-88) were studied. Of these 32 patients had normal (NR) and four patients had abnormal (AR) serum cortisol responses to synacthen as defined by the cut off for the Roche method.

The median, lower limit and upper limit of analytes according to method for the 32 NR and four AR are shown in Table 1. The Abbott method gave results that were about $20 \%$ lower than the Roche method. Salivary cortisone concentrations were approximately 3 fold higher than the equivalent salivary cortisol concentrations.

Correlation of salivary cortisol with the Roche serum cortisol was bimodal, intersecting at the CBG saturation level of a serum cortisol of $600 \mathrm{nmol} / \mathrm{L} \quad(\mathrm{y}=$ $0.0214 \mathrm{x}-2.0105 \mathrm{R}^{2}=0.6037<600 \mathrm{nmol} / \mathrm{L} ; \mathrm{y}=0.0852 \mathrm{x}-42.666 \mathrm{R}^{2}=0.6836$ $\geq 600 \mathrm{nmol} / \mathrm{L}$ ) as shown in Figure 1 . Correlation of salivary cortisone with the Roche serum cortisol (Figure 2) was linear $\left(\mathrm{y}=1.072 \mathrm{x}-13.939 \mathrm{R}^{2}=0.7511\right)$ with minimal pivot around the CBG saturation point. Based on these correlations, adequate salivary cortisol and cortisone responses to synacthen were extrapolated from a serum cortisol (Roche) cut-off of $550 \mathrm{nmol} / \mathrm{L}$ to be $15 \mathrm{nmol} / \mathrm{L}$ and $45 \mathrm{nmol} / \mathrm{L}$ respectively (Table 2). 


\section{Discussion}

We used a LCMSMS method for the analysis of salivary cortisol and cortisone based upon a previously described robust method $[4,5]$ to facilitate the investigation of adrenal disorders. The advantages of salivary cortisol analysis over blood cortisol analysis in the investigation of Cushing's syndrome are well-recognised. These include more accurate reflection of biologically active free plasma cortisol, noninvasiveness, stress free for the patient, no risk of needle stick injury and ease of collection allowing potential home testing and posting of samples. Less wellrecognised are the potential benefits of salivary analysis over blood analysis in investigating adrenal hypofunction including those patients with either difficult venous access and/or altered CBG concentrations.

Salivary cortisol had a bimodal correlation with serum cortisol, which is consistent with previous reports $[1,3]$. The rapid increase in salivary cortisol at serum cortisol concentrations greater than $600 \mathrm{nmol} / \mathrm{L}$, suggests circulating $\mathrm{CBG}$ is saturated with cortisol at a serum cortisol concentration of $600 \mathrm{nmol} / \mathrm{L}$ [3]. Compared to salivary cortisol, salivary cortisone concentrations were threefold higher and had a closer linear correlation with serum cortisol. Salivary cortisol concentrations are dependent not only on circulating free cortisol but also on its metabolism by salivary $11 \beta$-HSD2 to cortisone, whereas changes in salivary cortisone concentrations are solely due to its conversion from salivary cortisol since adrenal stimulation does not affect circulating cortisone levels $[2,3]$. These data suggest that salivary cortisone may be the preferred analyte in the assessment for adrenal function.

Abbott serum cortisol results were 20\% lower than Roche serum cortisol results, which is well-recognised [6] and evident from EQA schemes. This has, therefore, led to the concept of assay specific cut-offs for defining normal serum cortisol responses to synacthen $[6,8]$. Variability in immunoassay and non-immunoassay performance indicates that LC-MSMS salivary cortisol cut-offs defined in this study may not be transferable to salivary cortisol immunoassays.

There are insufficient data to define reference intervals for salivary cortisol and cortisone. Cut-off values of $15 \mathrm{nmol} / \mathrm{L}$ for salivary cortisol and $45 \mathrm{nmol} / \mathrm{L}$ for salivary cortisone were, therefore, extrapolated from established serum cut-off cortisol value of $550 \mathrm{nmol} / \mathrm{L}$ and would have correctly classified all patients into those with normal and those abnormal responses to synacthen. Cortisol responses to intramuscular synacthen are similar to those following intravenous synacthen [7]. We, therefore, plan to offer synacthen tests with salivary cortisol and cortisone measurement for suspected adrenal hypofunction routinely in patients with limited venous access and those with suspected altered CBG concentrations . 


\section{References}

1. Vining RF, McGinley RA et al. Salivary cortisol: a better measure of adrenal cortical function than serum cortisol. Ann Clin Biochem 1983; 20: 329-335

2. Perogamvros I, Keevil BG et al. Salivary Cortisone Is a potential Biomarker for Serum Free Cortisol. J Clin Endocrinol Metab 2010; 95(11) 4951-4958

3. Wood P. Salivary Steroid assays - research or routine? Ann Clin Biochem 2009; 46: 183-196

4. Perogamvros I, Owen LJ, Keevil BG et al. Measurement of salivary cortisol with liquid chromatography mass spectrometry in patients undergoing dynamic endocrine testing. Clinical Endocrinolgy 2010; 72: 17-21

5. Perogamvros I, Owen L et al. Simultaneous measurement of cortisol and cortisone in human saliva using liquid chromatography-tandem mass spectrometry: Application in basal and stimulated conditions. $J$ Chromatography B 2009; 877: 3771-3775

6. El-Farhan N, Pickett A, Ducroq D, et al. Method-specific serum cortisol responses to the adrenocorticotrophin test: comparison of gas chromatography-mass spectrometry and five automated immunoassays. Clin Endocrinol (Oxf). 2013;78:673-80.

7. Barth JH, Butler GE, Hammond P. Short Synacthen test for suspected adrenal failure. In Hooper J, Sherwood R, Marshall W (eds) Biochemical Investigations in Laboratory Medicine. ACB venture publications. $2001 \mathrm{pp}$ 170-171

8. National Institute for Health and Care Excellence (2010). [Clinical Knowledge Summaries. Addison's Disease]. http://cks.nice.org.uk/addisons-disease (accessed 26/01/2015). 


\begin{tabular}{|c|c|c|c|c|c|c|c|c|c|c|c|c|c|c|c|c|c|c|c|c|c|c|c|c|}
\hline \multirow{3}{*}{$\begin{array}{c}\text { Time } \\
(\operatorname{mins})\end{array}$} & \multicolumn{6}{|c|}{ Serum Roche nmol/L } & \multicolumn{6}{|c|}{ Serum Abbott nmol/L } & \multicolumn{6}{|c|}{ Sal Cortisol nmol/L } & \multicolumn{6}{|c|}{ Sal Cortisone nmol/L } \\
\hline & \multicolumn{3}{|c|}{ NR (32) } & \multicolumn{3}{|c|}{ AR (4) } & \multicolumn{3}{|c|}{ NR (32) } & \multicolumn{3}{|c|}{ AR (4) } & \multicolumn{3}{|c|}{ NR (32) } & \multicolumn{3}{|c|}{ AR (4) } & \multicolumn{3}{|c|}{ NR (32) } & \multicolumn{3}{|c|}{ AR (4) } \\
\hline & Media & LL & $\mathrm{UL}$ & $\begin{array}{c}\text { Media } \\
\mathrm{n}\end{array}$ & $\begin{array}{l}\mathrm{L} \\
\mathrm{L}\end{array}$ & $\begin{array}{l}\mathrm{U} \\
\mathrm{L}\end{array}$ & Media & LL & $\overline{\mathrm{UL}}$ & $\begin{array}{c}\text { Media } \\
n\end{array}$ & LL & $\overline{\mathrm{UL}}$ & $\underset{n}{\text { Media }}$ & LL & UL & $\underset{\mathrm{n}}{\text { Media }}$ & LL & $\mathrm{UL}$ & Media & LL & $\mathrm{UL}$ & Media & LL & UL \\
\hline $\mathbf{0}$ & 412 & $\begin{array}{r}14 \\
5\end{array}$ & 751 & 112.5 & 11 & $\begin{array}{r}19 \\
8\end{array}$ & $\begin{array}{r}329.1 \\
8 \\
\end{array}$ & $\begin{array}{r}115.5 \\
8\end{array}$ & 600.38 & 89.58 & 8.38 & $\begin{array}{r}157.9 \\
8\end{array}$ & 3.445 & $\begin{array}{r}1.0 \\
4\end{array}$ & $\begin{array}{r}9.2 \\
2\end{array}$ & 1.022 & $\begin{array}{r}0.66 \\
3\end{array}$ & $\begin{array}{r}2.6 \\
3\end{array}$ & 21.1 & $\begin{array}{r}8.7 \\
3\end{array}$ & $\begin{array}{r}48 . \\
2\end{array}$ & 5.185 & $\begin{array}{r}0.50 \\
2\end{array}$ & $\begin{array}{r}14 . \\
8\end{array}$ \\
\hline 30 & 699 & $\begin{array}{r}46 \\
0 \\
\end{array}$ & $\begin{array}{r}124 \\
1 \\
\end{array}$ & 266.5 & 27 & $\begin{array}{r}43 \\
7 \\
\end{array}$ & $\begin{array}{r}558.7 \\
8 \\
\end{array}$ & $\begin{array}{r}367.5 \\
8 \\
\end{array}$ & 992.38 & $\begin{array}{r}212.7 \\
8 \\
\end{array}$ & $\begin{array}{r}21.1 \\
8 \\
\end{array}$ & $\begin{array}{r}349.1 \\
8 \\
\end{array}$ & 15.6 & $\begin{array}{r}7.3 \\
4 \\
\end{array}$ & $\begin{array}{r}57 . \\
1 \\
\end{array}$ & 4.24 & $\begin{array}{r}0.32 \\
6 \\
\end{array}$ & $\begin{array}{r}6.8 \\
2 \\
\end{array}$ & 52 & $\begin{array}{r}28 . \\
5 \\
\end{array}$ & 184 & 16.05 & 1 & $\begin{array}{r}17 . \\
3 \\
\end{array}$ \\
\hline 60 & 798.5 & $\begin{array}{r}55 \\
3\end{array}$ & $\begin{array}{r}133 \\
8\end{array}$ & 328.5 & 34 & $\begin{array}{r}53 \\
1\end{array}$ & $\begin{array}{r}638.3 \\
8\end{array}$ & $\begin{array}{r}441.9 \\
8\end{array}$ & $\begin{array}{r}1069.9 \\
8\end{array}$ & $\begin{array}{r}262.3 \\
8\end{array}$ & $\begin{array}{r}26.7 \\
8\end{array}$ & $\begin{array}{r}424.3 \\
8\end{array}$ & 27.1 & $\begin{array}{r}14 . \\
1\end{array}$ & 86 & 5.1 & 0.28 & $\begin{array}{r}10 . \\
6\end{array}$ & 77.9 & $\begin{array}{r}38 . \\
9\end{array}$ & 144 & 18.4 & 1.25 & $\begin{array}{r}28 . \\
2\end{array}$ \\
\hline
\end{tabular}

Table 1 Median, lower limit (LL) and upper limit (UL) for Normal responders (NR) and Abnormal Responders (AR) for each method and analyte

\begin{tabular}{|l|r|}
\hline & $\begin{array}{l}\text { Cut-off } \\
\text { values } \\
\text { (nmol/L }\end{array}$ \\
\hline Serum Cortisol (Roche) & 550 \\
\hline Serum Cortisol (Abbott) & 440 \\
\hline *Salivary cortisol & 15 \\
\hline *Salivary cortisone & 45 \\
\hline
\end{tabular}

Table 2 Cut-off values for defining adequate adrenal function during a $0.25 \mathrm{mg}$ synacthen test.

*Corresponding to serum cortisol cut-offs derived from salivary cortisol/cortisone correlations with serum cortisol 


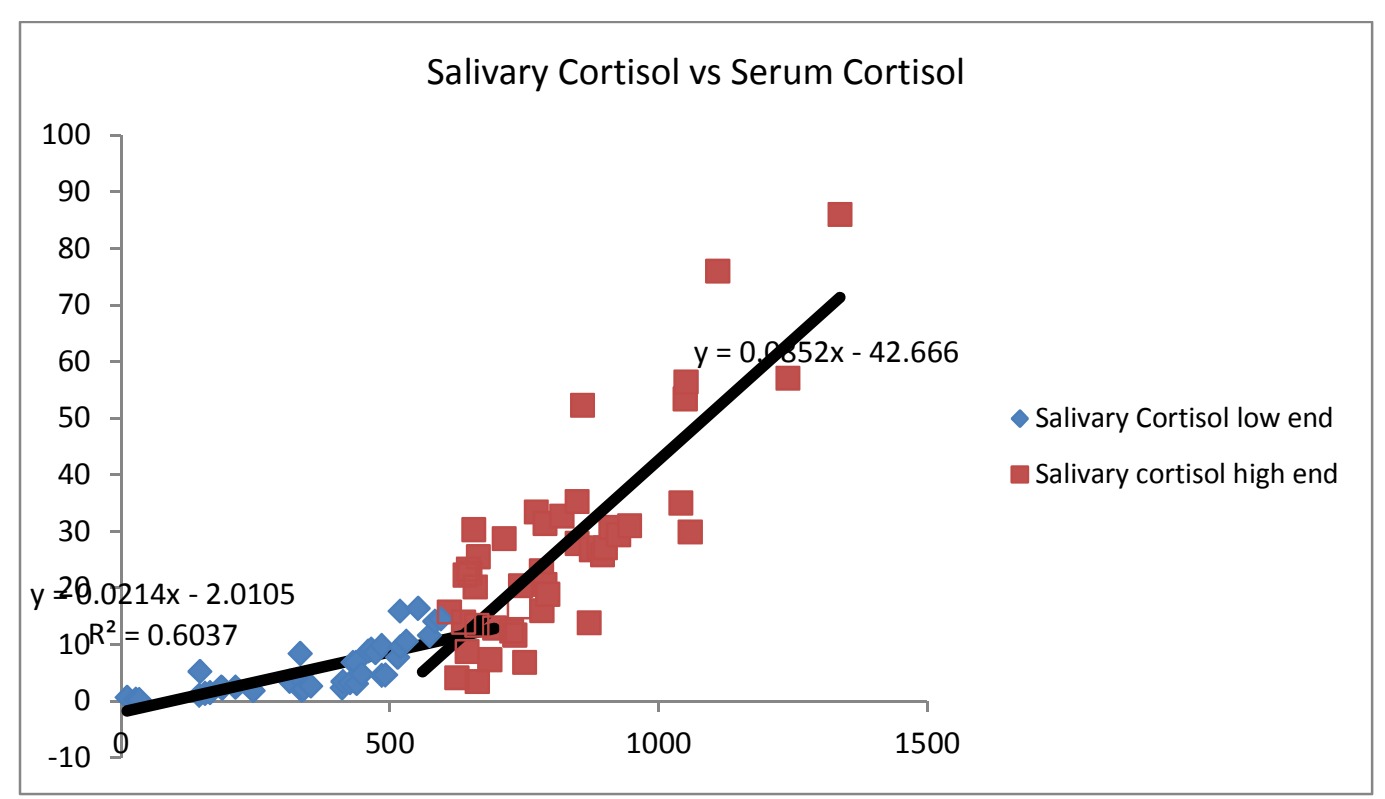

Figure 1 Salivary Cortisol vs Serum cortisol (nmol/L)

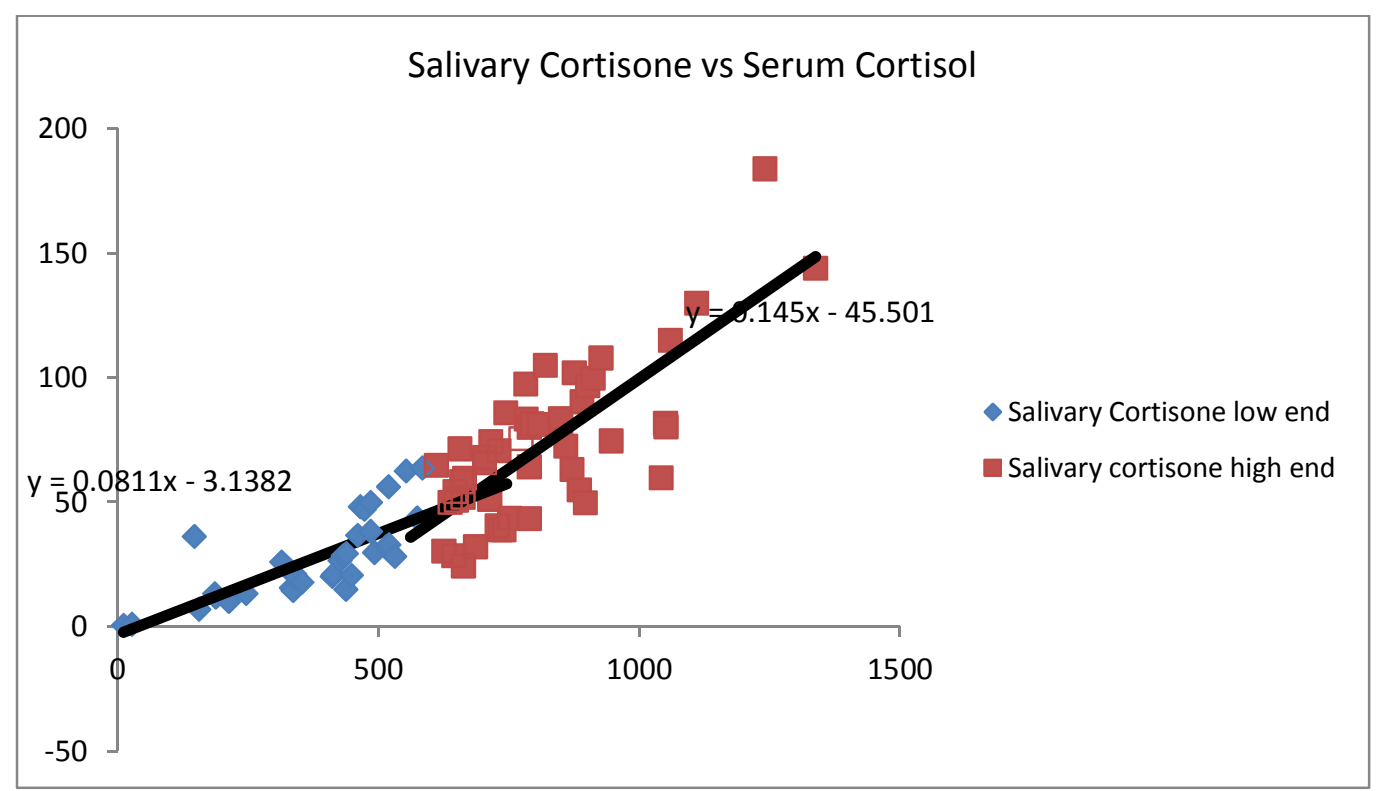

Figure 2 Salivary Cortisone vs Serum cortisol (nmol/L) 